\title{
Dilatometric Cycles in the Study of Precipitation of Intermetallic Phases in Duplex Stainless Steels
}

\author{
Elki C. Souza ${ }^{a}$ (D), Raiched F. Bueno ${ }^{b}$ (D), Carlos A. Fortulan ${ }^{c}$ (D), João M. D. A. Rollo \\ ${ }^{a}$ Universidade Federal do Tocantins (UFT), Gurupi, TO, Brasil \\ ${ }^{b}$ Universidade de São Paulo (USP), Escola de Engenharia de São Carlos, Departamento de Engenharia \\ Mecânica, São Carlos, SP, Brasil \\ 'Universidade de São Paulo (USP), Escola de Engenharia de São Carlos, Departamento de Engenharia \\ de Materiais, São Carlos, SP, Brasil
}

Received: June 9, 2020; Revised: August 20, 2020; Accepted: September 6, 2020

\begin{abstract}
Duplex stainless steels (DSS) are used in off-shore platforms due to their good properties resulting from the combination of two phases, namely austenite and ferrite. Secondary intermetallic phases, such as alpha prime $\left(\alpha^{\prime}\right)$ and sigma $(\sigma)$, which are harmful, can be formed at temperatures above $400{ }^{\circ} \mathrm{C}$, or by a casting process. This study investigates the formation of sigma phase by thermal cycles running in a dilatometer $\left(800^{\circ} \mathrm{C}, 850{ }^{\circ} \mathrm{C}, 900{ }^{\circ} \mathrm{C}\right.$ and $\left.1,000{ }^{\circ} \mathrm{C}\right)$ for $1 \mathrm{~h}$, and at $850{ }^{\circ} \mathrm{C}$ for $3 \mathrm{~h}$ and $7 \mathrm{~h}$. The optical microscopy of the DSS microstructure subjected to 800,850 and $900{ }^{\circ} \mathrm{C}$ for one hour revealed a small fraction of $\sigma$ phase with nucleation in the contour of ferrite/austenite phases, and tests by ferritoscope indicated a decrease $(\sim 4 \%)$ in a magnetic fraction (ferrite). However, samples subjected to dilatometric cycles at $850{ }^{\circ} \mathrm{C}$ for 3 hours showed an $18 \%$ decrease in the magnetic phase and quantitative metallography revealed a $33 \%$ fraction of $\sigma$ phase precipitated in the ferrite phase. Tests conducted at $850^{\circ} \mathrm{C}$ for 7 hours indicated a high fraction of $\sigma$ phase precipitated (approximately $50 \%$ ), starting in the grain boundary, austenite/ferrite, and advancing in ferrite grain.
\end{abstract}

Keyword: Duplex Stainless Steel (DSS), Dilatometer, Sigma Phase, Quantitative Metallography, Ferristoscope, Intermetallic Phases.

\section{Introduction}

Duplex stainless steels (DSS) are based on Fe-Cr-Ni alloys that show a favorable combination of two phases in equal fractions, namely austenite $(\gamma)$ and ferrite $(\delta)$, with chemical elements called austenitizing ( $\mathrm{Ni}, \mathrm{N}, \mathrm{C}, \mathrm{Mn}, \mathrm{Cu})$ and ferritizing $(\mathrm{Cr}, \mathrm{Mo}, \mathrm{Si})$ stabilizers $^{1-4}$, which, respectively, confer ductility and stress corrosion resistance. In general, carbide precipitation does not occur, due to the very low contents of carbon in DSS. The good properties of this steel class can be attributed to the low $\mathrm{C}$ content and a two-phase microstructure composed of elements of stabilizing ferrite and austenite alloys ${ }^{5,6}$. Consequently, duplex stainless steels can be used under most severe temperature conditions and in chloride environments, where austenitic steels are usually susceptible to pitting, cracking and stress corrosion ${ }^{2-4,7,8}$.

Alloying elements, such as $\mathrm{Cr}$, Mo and $\mathrm{N}$ in DSSs provide good corrosion properties in caustic, acid and marine environments ${ }^{4,9}$. Chan and Tjong $^{5}$ studied the precipitation of sigma and chi phases at $700-900{ }^{\circ} \mathrm{C}$ and the spinodal decomposition of ferritic grains into $\mathrm{Cr}$-rich and $\mathrm{Cr}$-poor phases at $350-550{ }^{\circ} \mathrm{C}$, respectively, in DSSs. The results showed Cr-rich $\alpha$ '-precipitates formed at $350-550{ }^{\circ} \mathrm{C}$ and intermetallic phase formed at $700-900{ }^{\circ} \mathrm{C}$ are deleterious to corrosion resistance to highly alloyed steels, due to the formation of such phases for the depletion of $\mathrm{Cr}$ or $\mathrm{Cr} / \mathrm{Mo}$ content in the matrix adjacent to the precipitates.

*e-mail: elkicsouza@uft.edu.br
In duplex stainless steels, solidification begins at approximately $1,450{ }^{\circ} \mathrm{C}$ with the formation of ferrite $(\alpha)$, which gives rise to austenite $(\gamma)$ close to $1,300^{\circ} \mathrm{C}$. Carbides $\mathrm{M}_{7} \mathrm{C}_{3}(\mathrm{M}=$ metal $)$ precipitate between $950^{\circ} \mathrm{C}$ and $1,050{ }^{\circ} \mathrm{C}$ in grain boundaries, and $\mathrm{M}_{23} \mathrm{C}_{6}$ is formed below $950{ }^{\circ} \mathrm{C}^{10}$. Sigma is an intermetallic, non-magnetic, and very hard phase $(\sigma)$, which causes embrittlement when precipitated in solid state between 600 and $950{ }^{\circ} \mathrm{C}$ with loss of toughness ${ }^{10-12}$. In DSS, it preferably nucleates at the $\alpha / \gamma$ interface, which is incoherent with the matrix duplex; precipitation occurs in raw double-cast stainless steels and can consume the entire ferrite phase, represented by reaction $\alpha=\sigma+\gamma^{*}$ (eutectoid), where $\gamma^{*}$ is a secondary austenite containing less Mo and $\mathrm{Cr}$ than untransformed austenite ${ }^{11-14}$.

Sigma precipitates can appear in various series of stainless steels, thus leading to undesirable effects, such as decreased corrosion resistance, and loss of both weldability and mechanical properties ${ }^{15-18}$. The $\sigma$ phase can precipitate in elevated-temperature processes, such as casting, aging, welding and forging. The prediction of its precipitation is difficult when the chromium content is above $20 \mathrm{wt} \%$ in stainless steels, as in DSS grade. The presence of ferrite stabilizers in stainless steels $(\mathrm{Cr}, \mathrm{Mo}, \mathrm{Si})$ can lead to a quick $\sigma$ phase formation, therefore, the understanding of the $\delta \rightarrow \sigma$ phase transformation mechanism is fundamental for both prediction and control of stainless steels properties ${ }^{16,17,19-23}$.

A brief review of the literature on sigma phase revealed it was first found in 1907, in the Fe-Cr binary system as 
an intermetallic compound of $30 \mathrm{wt} . \%$ to $50 \mathrm{wt} . \% \mathrm{Cr}$, and twenty years later, it was detected in the $\mathrm{Fe}-\mathrm{Cr}-\mathrm{Ni}$ ternary system ${ }^{17}$. Its crystal structure in the $\mathrm{Fe}-\mathrm{Cr}$ binary system was examined and exhibited slower precipitation kinetics in the $\mathrm{Fe}-\mathrm{Cr}$ alloy system than in $\mathrm{Fe}-\mathrm{Cr}-\mathrm{Mo}$ and $\mathrm{Fe}-\mathrm{Cr}-\mathrm{Si}$ ternary systems. In 1966, the $\sigma$ phase was observed in austenitic stainless steels, in over fifty transition alloys, Fe-Cr-X alloy ternary systems (where $\mathrm{X}$ is a transition metallic element, such as Ni, Mo, Mn, or a non-metallic element, e.g., Si: $\mathrm{Fe}-\mathrm{Cr}-\mathrm{Si}$ ), and binary systems, like $\mathrm{Fe}-\mathrm{V}, \mathrm{Re}-\mathrm{Cr}$, Mo-Re, Ta-Al, W-Te, Ta-V, Zr-Ir, Nb-Pd, Ti-Mn, Nb-Fe ${ }^{17}$.

This study investigates the existence and fraction of transformation of the intermetallic sigma phase by heating in a dilatometer at $20{ }^{\circ} \mathrm{C}$ per minute towards obtaining information about the influence of both temperature and isothermal time on the volumetric fraction of $\sigma$ phase in stainless steel of duplex structure. The materials produced were characterized by optical microscopy and magnetic phase detection via ferritoscope for the estimate of fraction of the phases present in DSS. The results of thermal cycling in dilatometer and quantitative tests were used for the plotting of time-temperature-transformation (TTT) curves. The morphology, microstructure and mechanical properties of the microhardness of the phases in DSS were also investigated.

\section{Materials and Methods}

Duplex stainless steel DIN W No 14517 (Cr26Ni6Mo3Cu3) was prepared in an electrical induction furnace and thermally treated at $1,050{ }^{\circ} \mathrm{C}$ for $1 \mathrm{~h}$ followed by water quenching. Table 1 shows its chemical composition and the pitting resistance equivalent number (PREn).

Cylindrical stainless steel austenitic-ferrite $\left(\mathrm{Cr}_{26} \mathrm{Ni}_{6} \mathrm{Mo}_{3} \mathrm{Cu} 3\right)$ specimens of $\varnothing 6 \mathrm{~mm}$ by $25 \mathrm{~mm}$ length were subjected to dilatometric thermal cycles in a model DIL402C $\mathrm{NETZSCH}$ dilatometer at $20^{\circ} \mathrm{C} \cdot \mathrm{min}^{-1}$ heating rate at 800 , 850,900 and $1,000{ }^{\circ} \mathrm{C}$, remaining at that temperature level for 1 hour and at $850^{\circ} \mathrm{C}$ for 3 and 7 hours in helium gas environment. The samples were then cooled at $20^{\circ} \mathrm{C} \cdot \mathrm{min}^{-1}$ to room temperature. The fraction of sigma phase transformed as a function of isothermal temperature and time was checked by optical microscopy and testing via ferritoscope.

Dilatometer cycles were also performed on an Adamel Lhomargy dilatometer (DT1000) that can reproduce ultrahigh heating and cooling rates. Cylindrical samples of $\varnothing 2 \mathrm{~mm}$ by $12 \mathrm{~mm}$ length were subjected to dilatometric cycles from $3{ }^{\circ} \mathrm{C} . \mathrm{s}^{-1}$ to $1100{ }^{\circ} \mathrm{C}$ heating, remaining at this level for $10 \mathrm{~min}$ and then being cooled to $100^{\circ} \mathrm{C} . \mathrm{s}^{-1}$ for the respective $700{ }^{\circ} \mathrm{C}, 750{ }^{\circ} \mathrm{C}, 800{ }^{\circ} \mathrm{C}$ and $850{ }^{\circ} \mathrm{C}$ isotherms for 0.67 and $1.33 \mathrm{~h}$, then cooled to $10{ }^{\circ} \mathrm{C} . \mathrm{s}^{-1}$ until room temperature, under helium gas environment for the full cycle. Transformation-time-temperature (TTT) curves were drawn for the evaluation of the sigma phase precipitation kinetics and DSS analysis of $\sigma$ time and dissolution kinetics. Such analyses enabled an experimental determination of initial thermal treatment, $\sigma$ dissolution temperature and time, and data required for the evaluation of the material's solubilization temperature, thus obtaining $1,050{ }^{\circ} \mathrm{C}$ dissolution temperature and 15 min time. $1,100^{\circ} \mathrm{C}$ was the temperature chosen for solubilization, with no occurrence of abnormal grain growth (secondary recrystallization).

Measurements of magnetic phase percentage for the determination of the percentage of ferrite (magnetic phase) by a Fischer Ferritscope (non-destructive magnetic method) were performed for 25 tests in different parts for each sample.

Beraha's chemical reagent revealed the DSS microstructure, austenite and ferrite, and sigma phases ${ }^{3,7,8}$, and then quantitative metallography was performed in eight fields for each sample with LEICA light microscope, equipped with a Motic Advanced 3.2 image analyzer system.

Vickers microhardness (HV) indenter (with $100 \mathrm{~g}$ load from the surface to the interior on the cross-sections) used LEICA VMHT-MOT microhardness tester to characterize the microhardness of the phases present in DSS.

The fraction of ferrite phase (magnetic phase) in the absence of intermetallic precipitation was given by Equation 1:

$\% \alpha=100-\% \gamma$

where $\alpha$ and $\gamma$ are the ferrite and austenite phases, respectively.

Knowledge of the fraction of the ferrite phase (before the precipitation of intermetallic phases) enables the estimation of fraction of intermetallic phase (which is non-magnetic) by

$\% \alpha_{1}=100-\% \gamma-\% \sigma$ or $\% \alpha_{1}=\% \alpha-\% \sigma$

Therefore,

$\% \sigma=\% \alpha-\% \alpha_{1}$

where $\sigma$ is an intermetallic phase and $\alpha_{1}$ is the ferrite phase after part has been consumed by sigma phase.

\section{Results and Discussion}

\subsection{Sigma phase precipitation by dilatometer tests in duplex stainless steels}

Figure 1 shows the curves obtained by dilatometry for duplex stainless steel in four different isotherms at $20^{\circ} \mathrm{C}$ per minute heating rate. The dilatograms showed the reactions of precipitation of intermetallic phases, since they cause dimensional alterations in the samples. The sigma phase precipitation leads to a contraction in the material ${ }^{6,9}$, therefore, a shrinkage was observed from a change in the dilatometric curve decay, readily detected at $850^{\circ} \mathrm{C}$ for $3 \mathrm{~h}$ (see Figure 1). Figure 2 displays the dilatogram curves of three isotherms at $800^{\circ} \mathrm{C}, 850{ }^{\circ} \mathrm{C}$ and $900{ }^{\circ} \mathrm{C}$.

Dilatometry enabled measurements of the variation length of the specimen (expansion or contraction) subjected to a controlled temperature program for thermal cycles.

Table 1. Chemical composition and pitting resistance equivalent number (PREn) of superduplex stainless steel.

\begin{tabular}{|c|c|c|c|c|c|c|c|c|c|c|}
\hline Elements & $\mathrm{C}$ & $\mathbf{S i}$ & Mn & $\mathbf{P}$ & $\mathrm{S}$ & Mo & $\mathrm{Cr}$ & $\mathbf{N i}$ & $\mathbf{N}$ & $\mathrm{Cu}$ \\
\hline (\%wt.) & 0.026 & 0.84 & 1.47 & 0.026 & 0.014 & 3.22 & 25.98 & 6.44 & 0.219 & 2.29 \\
\hline
\end{tabular}


A generic equation (Equation 4) can calculate the variation in the sample length as a function of temperature variation:

$$
\Delta L=\alpha \cdot L_{o} . \Delta T
$$

where $\Delta \mathrm{L}$ is the length variation (in $\mathrm{mm}$ ), $\alpha$ is the linear expansion coefficient $\left(\right.$ in $\left.{ }^{\circ} \mathrm{C}^{-1}\right), \mathrm{L}_{\mathrm{o}}$ is the initial length (in $\mathrm{mm}$ ), and $\Delta \mathrm{T}$ is the temperature variation (in ${ }^{\circ} \mathrm{C}$ ). $\alpha$ is the average linear expansion coefficient between temperatures $\mathrm{T}_{1}$ and $\mathrm{T}_{2}$, measured in ${ }^{\circ} \mathrm{C}^{-1}$.

The sigma phase precipitates between $600{ }^{\circ} \mathrm{C}$ and $1,000{ }^{\circ} \mathrm{C}$ in stainless steels, and its structure is body-centered tetragonal crystalline. In duplex stainless steels, the ferrite phase exhibits a cubic body-centered structure, whereas the austenite phase displays a face-centered cubic one. When $\sigma$ phase precipitates

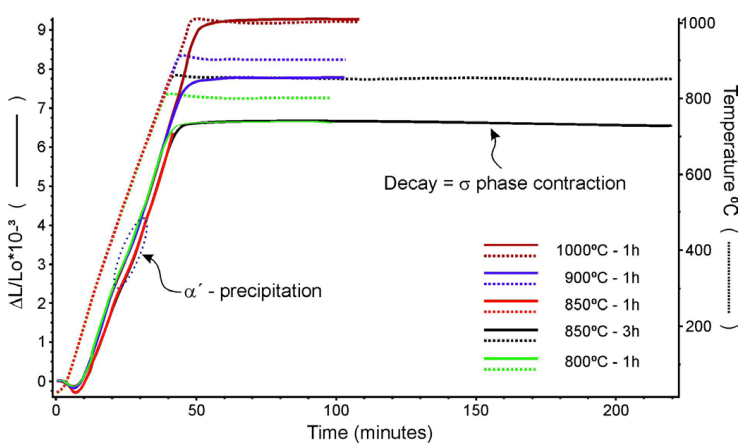

Figure 1. Dilatogram curves at $20^{\circ} \mathrm{C}$ per minute and isotherms at $800^{\circ} \mathrm{C}, 850^{\circ} \mathrm{C}, 900^{\circ} \mathrm{C}$ and $1000^{\circ} \mathrm{C}$ obtained by dilatometry.

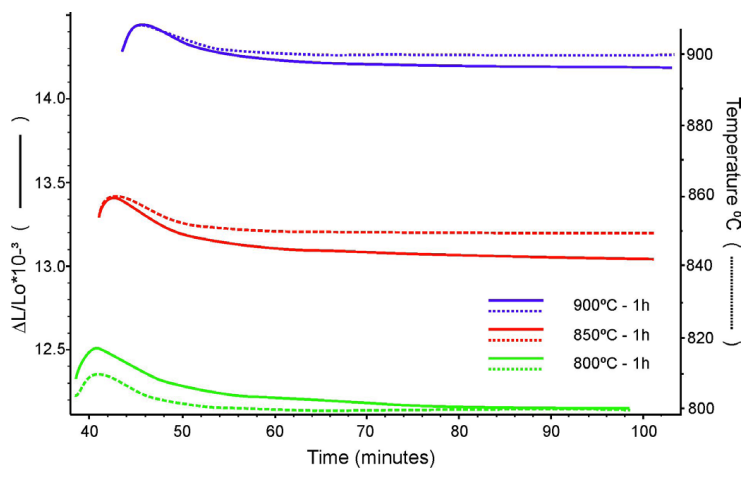

Figure 2. Dilatogram curves showing the levels of isotherms at $800^{\circ} \mathrm{C}, 850{ }^{\circ} \mathrm{C}$ and $900{ }^{\circ} \mathrm{C}$.

(a)

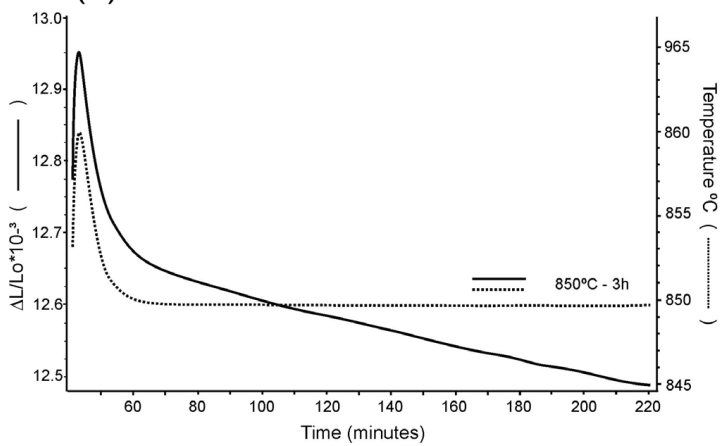

on $\delta$-ferrite to $\sigma$ phase $(\delta \rightarrow \sigma)$, it leads to a precipitate with high $\mathrm{Cr}$ in the region of $\delta$-ferrite. The $\sigma$ precipitation is not generally observable if austenitic stainless steels contain $\mathrm{Cr}$ below 20 wt.\%. However, when the $\mathrm{Cr}$ content is between $25 \mathrm{wt} \% \%$ and $30 \mathrm{wt} . \%, \sigma$ is quickly formed - it is the case of DSS in this study.

Figure $3 \mathrm{a}$ shows the dilatometric curve decay in an expanded region $\left(\Delta \mathrm{L} / \mathrm{L}_{\mathrm{o}}\right)$ of the plateau at $850{ }^{\circ} \mathrm{C}$ for 3 hours, and Figure $3 \mathrm{~b}$ displays the complete dilatometric curve: $20^{\circ} \mathrm{C} \cdot \mathrm{min}^{-1}$ heating rate, isotherm at 800 for 3 hours, and $20^{\circ} \mathrm{C} \cdot \mathrm{min}^{-1}$ cooling rate.

The dilatometer enabled evaluations of the precipitation period and temperature of intermetallic phases. The precipitation period and temperature of the $\sigma$ phase of duplex stainless steel were approximately 350 seconds $(\sim 6 \mathrm{~min})$ and $820^{\circ} \mathrm{C}$. At $830^{\circ} \mathrm{C}, 4 \%$ of $\sigma$ precipitated in 990 seconds $(\sim 17 \mathrm{~min})$.

\subsection{Microstructure of duplex stainless steels and sigma phase precipitation}

Figure 4 shows the microstructure (after Beraha chemical reagent attack) of duplex stainless steel before and after precipitation of sigma phase in a dilatometric thermal treatment at different temperatures $\left(800^{\circ} \mathrm{C}, 850{ }^{\circ} \mathrm{C}, 900^{\circ} \mathrm{C}\right.$ and $1000{ }^{\circ} \mathrm{C}$ ) for $1 \mathrm{~h}$ and $850{ }^{\circ} \mathrm{C}$ for $3 \mathrm{~h}$.

Figure 4 displays the sigma phase for "brightly scratches" into $\alpha$ phase enclosure for grain boundaries with $\gamma$ phase that are observed in the specimens treated for $1 \mathrm{~h}$ at 800 , 850 and $900^{\circ} \mathrm{C}$, and practically absent in the samples treated at $1000{ }^{\circ} \mathrm{C}$. Specimens treated at $850{ }^{\circ} \mathrm{C}$ showed a higher occurrence of sigma phase (brightly scratches), therefore, this temperature was chosen for a 3-hour step isotherm. According to Figure 4e, after a 3-hour isotherm, the "brightly scratches" increased in the DSS microstructure due to an increase in the precipitated sigma phase content.

\subsection{Percentage of magnetic phases via ferritoscope and vickers microhardness tests}

Table 2 shows the mean of twenty-five measurements taken by a ferritoscope relative to the volumetric fraction of the magnetic phases present in samples of as received duplex stainless steels, and after dilatometric tests at 800, 850, $900^{\circ} \mathrm{C}$ for $1 \mathrm{~h}$ and, one of them, at $850^{\circ} \mathrm{C}$ for 3 hours, whose decrease in the ferrite phase revealed it was consumed for the sigma phase formation. Table 3 shows the ferrite percentage obtained by optical microscopy for DSS subjected to tests

(b)

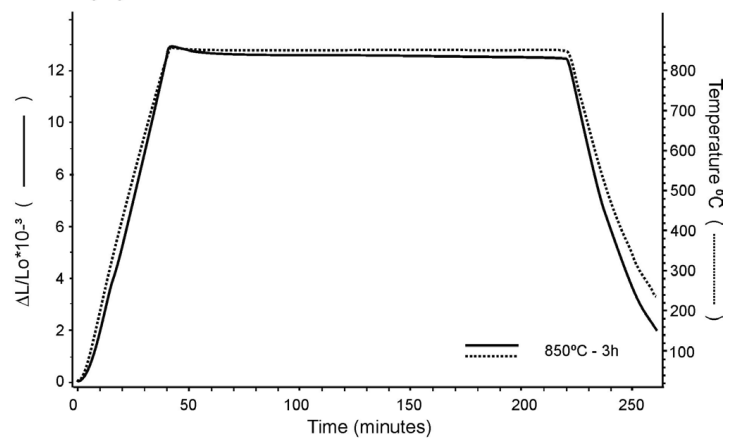

Figure 3. (a) Isothermal at $800{ }^{\circ} \mathrm{C}$ for $3 \mathrm{~h}$ by dilatometry, (b) Complete dilatometric curve at $800{ }^{\circ} \mathrm{C}$ for $3 \mathrm{~h}$. 

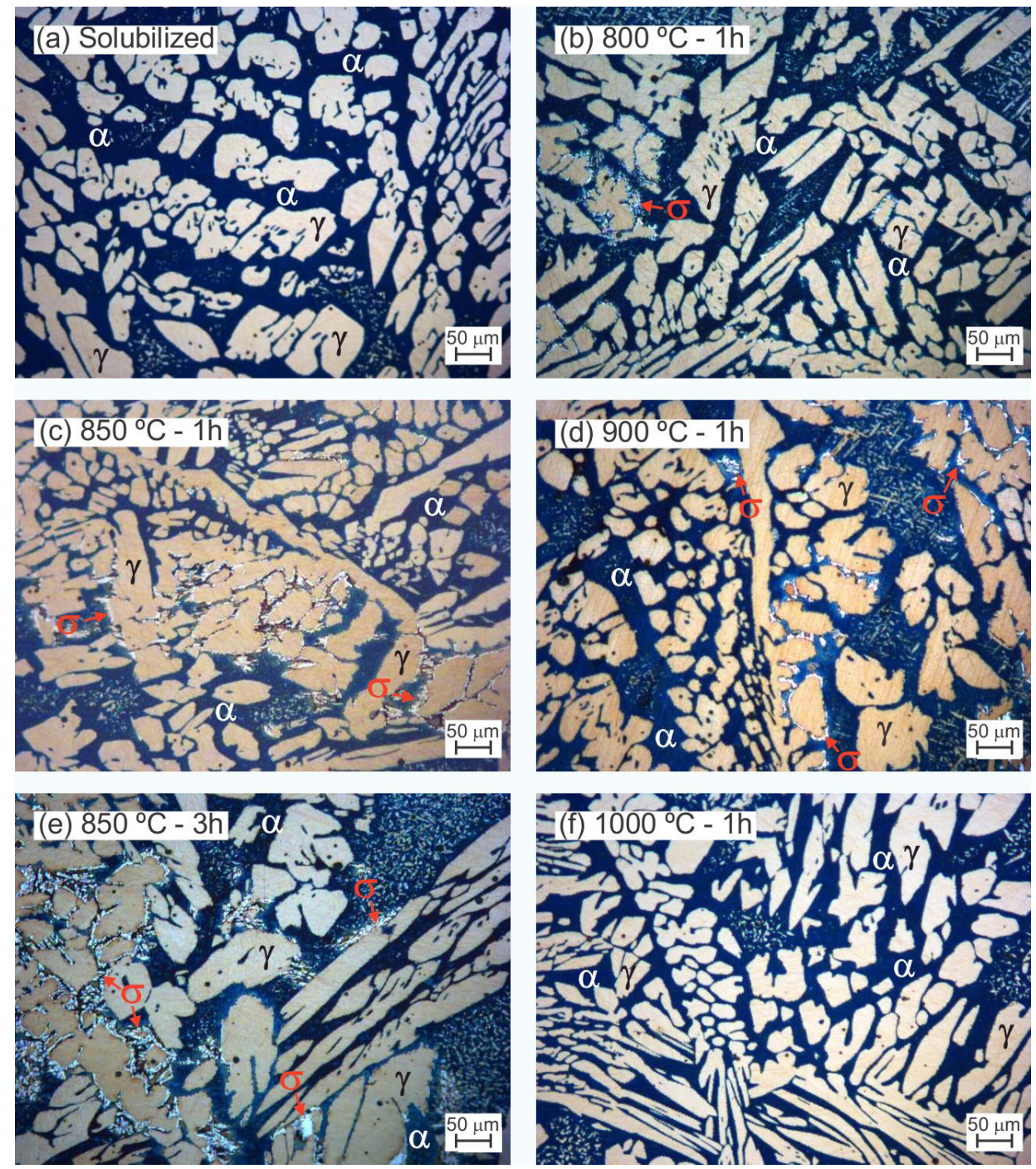

Figure 4. Microstructure of austenite-ferritic steels obtained from a thermal treatment at different temperatures. Microscope magnification: 200X.

Table 2. Results of ferritoscope measurements (volumetric fraction of magnetic phase - ferrite).

\begin{tabular}{ccccc}
\hline Test conditions & \% average & \% maximum & \% minimum & Standard deviations \\
\hline as received (solubilized) & 35.8 & 37.7 & 34.7 & 0.8 \\
\hline $1000{ }^{\circ} \mathrm{C}-1 \mathrm{~h}$ & 36.1 & 37.4 & 33.7 & 1.0 \\
\hline $900{ }^{\circ} \mathrm{C}-1 \mathrm{~h}$ & 34.7 & 36.3 & 31.8 & 1.0 \\
\hline $850{ }^{\circ} \mathrm{C}-1 \mathrm{~h}$ & 35.1 & 36.5 & 33.1 & 1.0 \\
\hline $800^{\circ} \mathrm{C}-1 \mathrm{~h}$ & 35.1 & 36.6 & 31.0 & 1.3 \\
\hline $850{ }^{\circ} \mathrm{C}-3 \mathrm{~h}$ & 29.6 & 32.9 & 27.2 & 1.6 \\
\hline
\end{tabular}

in dilatometers at $850{ }^{\circ} \mathrm{C}$ for $3 \mathrm{~h}$ and Vickers microhardness values of the phases present in the material.

The decrease in ferrite content and sigma phase formation detected by the ferritoscope for all materials subjected to tests in dilatometers are in accordance with the optical microscopy of the microstructure. At 800, 850 and $900{ }^{\circ} \mathrm{C}$, only a small fraction of sigma phase precipitated in the ferrite phase, where the testing via ferritoscope indicated a small decrease in the fraction of ferrite (magnetic), which was transformed into sigma phase (4\%), and tests performed at $850{ }^{\circ} \mathrm{C}$ for $3 \mathrm{~h}$ revealed $18 \%$ of sigma phase. The microstructure in Figure $4 \mathrm{e}$ indicates $33 \%$ of sigma phase by optical microscopy. The sigma phase showed a much higher Vickers microhardness value when compared to austenite and ferrite phases present in solubilized DSS.

Figure 5 displays the DSS microstructure after the sigma phase precipitation in a dilatometric test at $850{ }^{\circ} \mathrm{C}$ for 7 hours.

Sigma phase is rich in $\mathrm{Cr}$, Mo and $\mathrm{Si}$ (ferrite stabilizing elements) and its formation in DSS occurs basically from the ferrite phase. In addition, the diffusion of these elements sigma formers, particularly $\mathrm{Cr}$, is approximately 100 times 
Table 3. Percentage of ferrite obtained by optical microscopy and Vickers microhardness (HV) values of austenitic $(\gamma)$ and ferritic $(\alpha)$ phases for as received DSS and sigma phase $(\sigma)$ after thermal cycling at $850{ }^{\circ} \mathrm{C}$ for $3 \mathrm{~h}$.

\begin{tabular}{ccccc}
\hline \multirow{2}{*}{ Sample conditions } & $\begin{array}{c}\text { Optical microscopy } \\
\text { (\% ferrite) }\end{array}$ & $\gamma$ & \multicolumn{2}{c}{ Microhardness of Phases, Vickers (HV) } \\
\cline { 3 - 5 } & 46 & 230 & 285 & $\sigma$ \\
\hline solubilized & 31 & 230 & 265 & 480 \\
\hline $850^{\circ} \mathrm{C}-3 \mathrm{~h}$ & & & & \\
\hline
\end{tabular}
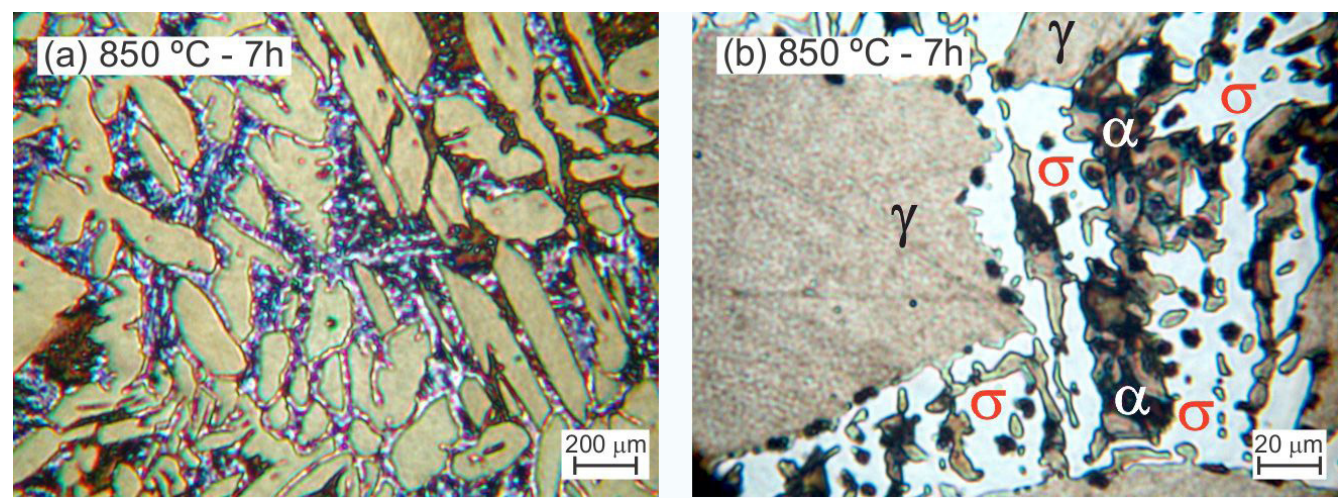

Figure 5. Microstructure of austenite-ferritic steels obtained from a thermal treatment at different temperatures. Microscope magnifications: (a) 50X; (b) 500X.

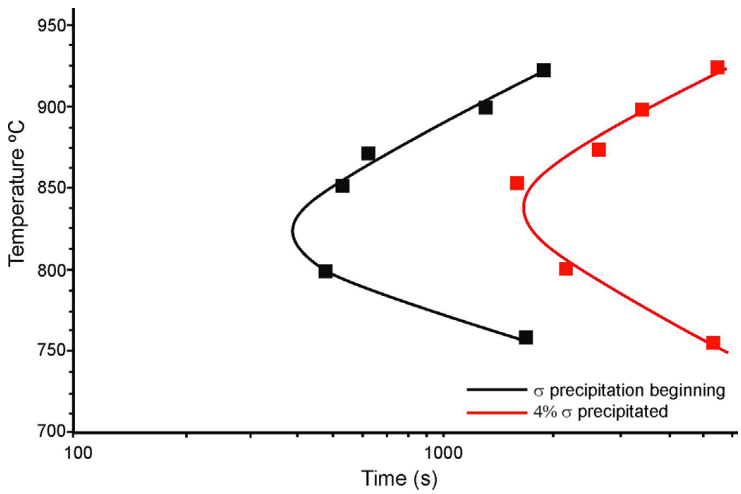

Figure 6. TTT (Time-Temperature-Transformation) diagrams of $\sigma$ phase precipitation. Black and red curves indicate start and termination, respectively.

faster in the ferrite phase than in the austenite phase, thus facilitating its formation. According to Figure 5, $\sigma$ starts to precipitate at the grain contours, i.e., $\gamma / \sigma$ interphase, and is intensified by 7-hours exposure at $850{ }^{\circ} \mathrm{C}$. Under such conditions, the amount of ferrite phase transformed from the sigma phase was approximately $50 \%$.

Figure 5 displays higher $\sigma$ phase precipitation kinetics at $850^{\circ} \mathrm{C}$ for 7 hours. Therefore, according to the micrographs, for longer isothermal times, the sigma phase precipitation, which started in the contours of the phases, advanced into ferrite grains.

\subsection{Time-Temperature-Transformation (TTT) diagrams}

DSS was investigated regarding the existence and precipitation of the sigma phase at various temperatures, towards the construction of a time-temperature-transformation diagram (TTT) by optical microscopy and magnetic phase detection (ferritoscopy), which describes heat treatment routes for reductions or even elimination of the volumetric fraction of sigma phase in stainless steel of a duplex structure. Figure 6 shows the TTT diagrams of the sigma phase between $750{ }^{\circ} \mathrm{C}$ and $950{ }^{\circ} \mathrm{C}$.

The precipitation of the sigma phase in raw duplex stainless steels is dramatic, since it can consume the entire ferrite phase, transforming it into sigma and austenitic phases through an eutectoid reaction. The latter differs from untransformed austenite, since it contains less molybdenum and chromium, thus causing serious deficiencies in the properties of the steel. The precipitation of $1 \%$ of $\sigma$ phase can decrease $50 \%$ the energy absorption in the impact test ${ }^{19,24}$. Since the sigma intermetallic phase is composed of several types of atoms, e.g., Cr, Mo and Fe, a quantitative solution of its precipitation-dissolution mechanism becomes complex. Therefore, qualitative solutions, such as plotting of time-temperature-transformation curves, can provide information on the speed of the sigma phase dissolution in matrices of duplex stainless steels.

Figure 6 shows the nose of the TTT curve is located in an $800{ }^{\circ} \mathrm{C}$ to $870{ }^{\circ} \mathrm{C}$ temperature range, which means the phase sigma precipitates faster.

No variation was observed in the magnetic phase content for $1 \mathrm{~h}$-thermal cycling at $1,000{ }^{\circ} \mathrm{C}$, which confirmed the absence of this intermetallic phase by optical micrographic observation and results of time-temperature-transformation (TTT) dilatometer curves. The precipitation ranges of $\sigma$ and $\alpha^{\prime}$ intermetallic phases can be determined so that heating and cooling rates imposed to this type of material in a dilatometry oven with similar industrial values. Fragility and corrosion in structural components made with austenitic-ferritic alloys were the causes of the non-spread of this class of material; therefore, prospective attempts of heat treatments for those alloys should be made towards meeting the requirements of the specific properties of the material, especially in abrasive and corrosive environments with applications at high temperature and mechanical stress. 


\section{Conclusions}

Results from optical microscopy and ferritoscope tests showed the DSS microstructure after 1h-thermal cycles in a dilatometer at different temperatures exhibited a small fraction of $\sigma$ phase precipitated in the ferrite phase with a small decrease (approximately 4\%) in the fraction of ferrite (magnetic) phase. On the other hand, tests conducted at $850{ }^{\circ} \mathrm{C}$ for three and seven hours showed the sigma phase in the grain boundaries of $\gamma / \alpha$ phases, which significantly decreased the magnetic phases due to the presence of a fraction of $\sigma$ phase, i.e., $\sim 15 \%$ (for $3 \mathrm{~h}$ ) and approximately $50 \%$ (for $7 \mathrm{~h}$ ). In this case, time was the determining factor in the largest fraction of sigma phase.

The highest sigma phase precipitation occurred in the nose of the TTT curves, at $\sim 850^{\circ} \mathrm{C}$. Such results alert to the avoidance of exposure of components made of DSS to this temperature range. However, when unavoidable, the exposure must be as fast as possible in heating or cooling processes.

\section{Acknowledgements}

The authors acknowledge Fundação de Amparo a Pesquisa do Estado de São Paulo (FAPESP) for its technical and financial support for this research, and Group Metal Stainless Steel and Special Alloys for the manufacture of the stainless steels.

\section{References}

1. Wang Y, Sun H, Li J, Li D, Li N. Pitting corrosion of thermally aged duplex stainless steels at different temperature for long time. Mater Res. 2019;22(6):e20180663.

2. Bettini E, Kivisäkk U, Leygraf C, Pan J. Study of corrosion behavior of a $22 \% \mathrm{Cr}$ duplex stainless steel: influence of nanosized chromium nitrides and exposure temperature. Electrochim Acta. 2013;113:280-9.

3. Souza EC, Rossitti SM, Fortulan CA, Rollo JMDA. Influence of ferrite phase content on the electrochemical properties of duplex stainless steels. Mater Res. 2016;20(1):21-9.

4. Rezende SC, Dainezi I, Apolinario RC, Sousa LL, Mariano NA. Influence of molybdenum on microstructure and pitting corrosion behavior of solution-treated duplex stainless steel in a lithium chloride solution. Mater Res. 2019;22(Suppl 1):e20190138.

5. Chan KW, Tjong SC. Effect of secondary phase precipitation on the corrosion behavior of duplex stainless steels. Materials. 2014;7(7):5268-304.

6. Menendez H, Devine TM. The influence of microstructure on the sensitization behavior of duplex stainless steel welds. Corros Sci. 1990;46(5):410-8.

7. Souza EC, Rossitti SM, Rollo JMDA. Influence of chloride ion concentration and temperature on the electrochemical properties of passive films formed on a superduplex stainless steel. Mater Charact. 2010;61(2):240-4.

8. Souza EC, Fortulan CA, Rollo JMDA. Microstructure by thermal attack under vacuum of a superduplex stainless steels and electrochemical behavior in $\mathrm{H}_{2} \mathrm{~S} / \mathrm{CO}_{2}$-saturated synthetic seawater. J Braz Chem Soc. 2018;29(9):1803-10.
9. Zhang B, Jiang Z, Li H, Zhang S, Feng H, Li H. Precipitation behavior and phase transformation of hyper duplex stainless steel UNS S32707 at nose temperature. Mater Charact. 2017;129:31-9.

10. Paulraj P, Garg R. Effect of intermetallic phases on corrosion behavior and mechanical properties of duplex stainless steel and super-duplex stainless steel. Adv Sci Technol Res J. 2015;9(27):87-105.

11. Pardal JM, Tavares SSM, Fonseca MC, De Souza JA, Côrte RRA, De Abreu HFG. Influence of the grain size on deleterious phase precipitation in superduplex stainless steel UNS S32750. Mater Charact. 2009;60(3):165-72.

12. Silva DDS, Basílio JM So, Souto CR, Gomes RM. Application of electromechanical impedance technique in the monitoring of sigma phase embrittlement in duplex stainless steel. Mater Sci Eng A. 2020;788:139457. http://dx.doi.org/10.1016/j. msea.2020.139457.

13. Magnabosco R. Kinetics of sigma phase formation in a duplex stainless steel. Mater Res. 2009;12(3):321-7. http://dx.doi. org/10.1590/S1516-14392009000300012.

14. Martins M, Casteletti LC. Heat treatment temperature influence on ASTM A890 GR 6A superduplex stainless steel microstructure. Mater Charact. 2005;55(3):225-33.

15. Lima HMLF, Bastos IN, Araújo WS, Martins M. Heat treatment effects on ASTM A890/A 890M GR 5A super duplex stainless steel passivity. Mater Res. 2018;20(Suppl 2):775-85.

16. Pohl M, Storz O, Glogowski T. Effect of intermetallic precipitations on the properties of duplex stainless steel. Mater Charact. 2007;58(1):65-71.

17. Hsieh CC, Wu W. Review article overview of intermetallic sigma $(\sigma)$ phase precipitation in stainless steels. ISRN Metallurgy. 2012;2012:1-16.

18. Hosseini VA, Karlsson L, Engelberg D, Wessman S. Timetemperature-precipitation and property diagrams for super duplex stainless steel weld metals. Weld World. 2018;62(3):517-33. http://dx.doi.org/10.1007/s40194-018-0548-z.

19. Warren AD, Harniman RL, Guo Z, Younes CM, Flewitt PEJ, Scott TB. Quantification of sigma-phase evolution in thermally aged 2205 duplex stainless steel. J Mater Sci. 2016;51(2):694707. http://dx.doi.org/10.1007/s10853-015-9131-9.

20. Zhu Z-H, Zang W-D, Tu X-H, Wang X-J, Li W. Effect of sigma phase precipitation on microstructure and properties of cast ZG0Cr26Ni5Mo3Cu3 duplex stainless steel under different heat treatments. Res Dev. 2018;15(3):182-8. http://dx.doi. org/10.1007/s41230-018-7226-z.

21. Yongqiang W, Hao S, Na L, Yanhao X, Hemin J. Effect of sigma phase precipitation on the pitting corrosion mechanism of duplex stainless steels. Int J Electrochem Sci. 2018;13:986887. http://dx.doi.org/10.20964/2018.10.38.

22. Fonseca GS, Oliveira PM, Diniz MG, Bubnoff DV, Castro JA. Sigma Phase in Superduplex Stainless Steel: Formation, Kinetics and Microstructural Path. Mater Res. 2017;20(1):24955. http://dx.doi.org/10.1590/1980-5373-mr-2016-0436.

23. Hosseini VA, Karlsson L, Wessman S, Fuertes N. Effect of sigma phase morphology on the degradation of properties in a super duplex stainless steel. Materials. 2018;11(6):933-53. http://dx.doi.org/10.3390/ma11060933.

24. Silva DDS, Raimundo RA, Torquato RA, Faria GL, Morales MA, Simões TA, et al. Low-field magnetic analysis for sigma phase embrittlement monitoring in thermally aged $22 \mathrm{Cr}$ duplex stainless steel. J Magn Magn Mater. 2020;513:167072. http:// dx.doi.org/10.1016/j.jmmm.2020.167072. 